Article

\title{
Territorial Responses of Nuthatches Sitta europaea-Evaluation of a Robot Model in a Simulated Territorial Intrusion ${ }^{\dagger}$
}

\author{
Christoph Randler*(D) and Erik Randler \\ Department of Biology, Eberhard Karls University of Tuebingen, Auf der Morgenstelle 24, \\ D-72076 Tübingen, Germany; erikrandler@gmail.com \\ * Correspondence: christoph.randler@uni-tuebingen.de \\ + This study is dedicated to the memory of Dr. Hans Löhrl.
}

Received: 17 November 2020; Accepted: 14 December 2020; Published: 17 December 2020

check for updates

Simple Summary: In birds, aggressive behavior is common to defend a territory. Experiments often use simulated territorial intrusion (STI). These STIs make use of playbacks of calls or song, sometimes in combination with a model or decoy. Here, we compared four different STI methods in nuthatches in the non-breeding season: playback only, playback combined with an inactive wooden model mounted on a robot device, playback and an active model mounted on a robot device, and playback with the robot device only. We observed the behavioral response, and found that all four experimental conditions were equal, but there was an order effect.

Abstract: In birds, aggressive behavior can be elicited in the field with a simulated territory intrusion (STI). Here, we compared four different STI methods in nuthatches in the non-breeding season: playback only, playback combined with an inactive wooden model mounted on a robot device, playback and an active model mounted on a robot device, and playback with the robot device only. In the control treatment, birds were not exposed to STI. Experiments were carried out in 12 territories. Behavioral observations included latency to approach, latency to start calling, time spent in the same tree, number of flyovers, minimum distance, number of individuals, number of flights into the tree, and number of calls. There was no significant influence of stimulus presentation. Nuthatches responded equally to all four experimental manipulations, but order of presentation had a strong influence.

Keywords: playback; simulated territorial intrusion; nuthatch; Sitta europaea; robotic model; decoy

\section{Introduction}

Territorial defense (aggression) is beneficial in species that defend resources, such as food or nesting places. This behavior has been linked to hormonal status as a proximate mechanism [1,2]. Aggressive behavior can be elicited in the field with a simulated territory intrusion (STI), which consists of placing a decoy or a model along with a conspecific song playback inside a territory [3]. STIs are useful to assess the behavioral response of a focal territorial individual [3]. STIs have been applied in many studies and have been used, for example, to assess song type matching, showing that individuals responded to a playback of a specific song with matching when the song variation was in the repertoire of the territory defender $[4,5]$. In addition, playbacks were used to assess phylogenetic relationships between different species (e.g., [6]). More generally, STI can be used to assess whether a species is territorial and defends a territory. STIs have also been used in studying the "dear enemy" hypothesis, where territory holders respond stronger to the STI of a stranger rather than to a well-known neighbor [7]. In addition, 
STIs showed a decline of the reaction during the breeding season [6], but also a change in the response in relation to breeding stages [7]. Thus, STIs are a well-established method in field experiments of birds.

Concerning the experimental procedure of STIS, playbacks, live birds, mounts/models, or the combination of playback and decoy have been applied in some cases [6,8,9]; "zero" stimuli as neutral objects have also been used [10]. During the advance of computer technology, robot models have also been used to simulate behavior, by including the movement component into such intrusion experiments. There are advantages and disadvantages of these approaches. Akçay et al. [11] compared a STI by a playback only versus an experiment where playback and mount have been combined. The mount condition elicited a higher aggression in some measured variables [11]. Therefore, by focusing on playback only, responses of focal birds may be different (or less realistic) because individuals may approach the playback source but by not seeing the intruder, behavior may change. An important question is whether bird behavior with and without mount is a good metric of natural territorial behavior. If birds simply behave less aggressively towards a song without the mount compared to song combined with mount, but the individual differences in aggression, or differences in aggression across contexts, can still be measured, then there should be no problem with a less intense response. It only becomes a problem if birds behave totally differently to a song STI compared to a song STI combined with a mount.

Thus, the situation of STI without a mount is considered somewhat less realistic because in simple playback experiments, the intruder is loud but invisible [11]. For example, in blackcaps (Sylvia atricapilla), males are singing quieter in response to playbacks [12]. Adding an immobile mount, thus, makes the intruder visible [11]. Combining playbacks with mounts, models, or decoys, STIs become more realistic and elicit more realistic or stronger reactions. There may also be environmental differences, as, e.g., open habitat dwelling species might be more likely to detect an intruder visually compared to dense forest-dwellers. In turn, however, this makes the interpretation of experimental approaches more complex because it is difficult to tease apart which factor is more effective for a specific response, the decoy, or the playback. Another general problem of models is that they do not move [13]. Although this is intuitive from a theoretical perspective, empirical evidence is needed to substantiate this claim. In studying heterospecific songbird responses in mobbing cuckoos (Cuculus canorus), Tryjanowski et al. [14] found no significant differences between a model and a real cuckoo. Similarly, there were no differences between live decoys and three-dimensional (3D) printed models in tree swallows (Tachycineta bicolor [15]). Further developments in computer animation techniques included robotic models, for example in satin bowerbirds (Ptilonorhynchus violaceus [16]), in playbacks with veery (Catharus fuscescens [17]), the magpie lark (Grallina cyanoleuca [18]) or in predator-prey situations [19]. The advent of interactive robots has increased the possibilities of interactive playbacks $[16,20,21]$. However, one must acknowledge between-species differences in aggression, territorial behavior and in courtship display when addressing movement of models.

Response to STI has mainly been studied during the breeding season in temperate zones and northern latitudes, respectively [22-24]. Most birds in temperate zones defend territories during the breeding season to have exclusive access to food resources needed for raising offspring [25]. Non-migratory birds should have a stronger motivation for territory defense in winter because they will retain their territory for the next breeding season (e.g., discussion in [26]). Further, autumn territories serve to ensure a winter food supply $[9,27,28]$. Food caching species should especially defend their territory to have exclusive access to their food storages during winter. When birds defend territories in winter, STI can be used to assess how strong this response is. We therefore focused on exploring the non-breeding territorial behavior in the nuthatch, Sitta europaea. In nuthatches, winter territorial defense is more intense than in spring [9], because food supply is more restricted, and territories are denser [8]. In this study, we wanted to assess territorial response of nuthatches in the non-breeding season. Further, we wanted to evaluate the responses towards a robotic model in comparison with playbacks and the combination of playbacks and a motionless decoy. 


\section{Materials and Methods}

\subsection{The Species}

The nuthatch is a small passerine species ( $\approx 22 \mathrm{~g}$; [29]), which defends territories outside the breeding season [28,30,31], a behavior that is rare in temperate bird species [31]. Territory defense and aggression in nuthatches differ between seasons with most severe conflicts occurring during September/October and in February/March $[8,9,32]$. Territory sizes of the nuthatch are rather small, given in a range of 1-2 ha, 2.2-3.4 ha, 0.68-1.21 ha, 0.8-4.3 ha [32-35]. Nuthatches are non-migratory birds, so that territory holders in autumn and winter may be the same individuals as in spring and summer [32]. Additionally, migratory behavior is nearly absent in nuthatches. Only a few nuthatches migrate through the study area [36]. For example, at a migration birdwatching spot about $50 \mathrm{~km}$ away, during 398 observation days with 1095 h between 1974 and 1997, only 147 nuthatches were noted between 22 August and 22 October [36].

\subsection{Fieldwork}

Observations were made from 21 October 2019 until 16 November 2019, from 8:00 to 13:00 during good weather conditions (no strong winds, no rain). Study locations were near Tübingen $\left(48^{\circ} 31^{\prime} \mathrm{N}, 9^{\circ} 3^{\prime} \mathrm{E}\right)$ and Rottenburg am Neckar $\left(48^{\circ} 28^{\prime} \mathrm{N}, 8^{\circ} 56^{\prime} \mathrm{E}\right)$ in Southwest Germany in deciduous forests [37,38]. We defined 12 territories for all experiments. We used only sample plots where territorial nuthatches were present in previous surveys. The focal animal sampling method was used [39]. Focal birds were not marked for individual recognition. Nonetheless, we consider our observations to be independent from each other as we kept a minimum distance of at least $298 \mathrm{~m}$ between study sites (mean: $998 \mathrm{~m}$ ). Taken together with the territory sizes cited above, it is unlikely that the same individual was observed at two territories simultaneously. Additionally, nuthatches are territorial year-round [32], suggesting that there are not many movements between already established territories. Further, new territories were established in August/September by the young of the year, so settlement had likely been finalized by the beginning of the study period [32].

STIs were presented in a randomized order to avoid order effects, in a counterbalanced design. The following experiments were carried out (Figure 1):

1. Playback of calls and model and robot device in motion (mounted onto the device and in motion);

2. Playback of calls and model presentation (mounted on the device but motionless);

3. Playback of calls and robot device in motion, but without a model (no mount on the device, but device in motion);

4. Playback of calls.

In addition to the experimental approaches, a baseline measurement was carried out once per territory (just at one time before an experiment). Here, we used the loudspeaker shifted on but with no playback (no sound) and no mount or device. This was to assess whether nuthatches respond to STIs in general in the non-breeding season. The baseline was measured before an STI experiment because we assumed that the subsequent experiment would not be influenced by this baseline measure. The baseline was randomly assigned to one of the four STIs. 

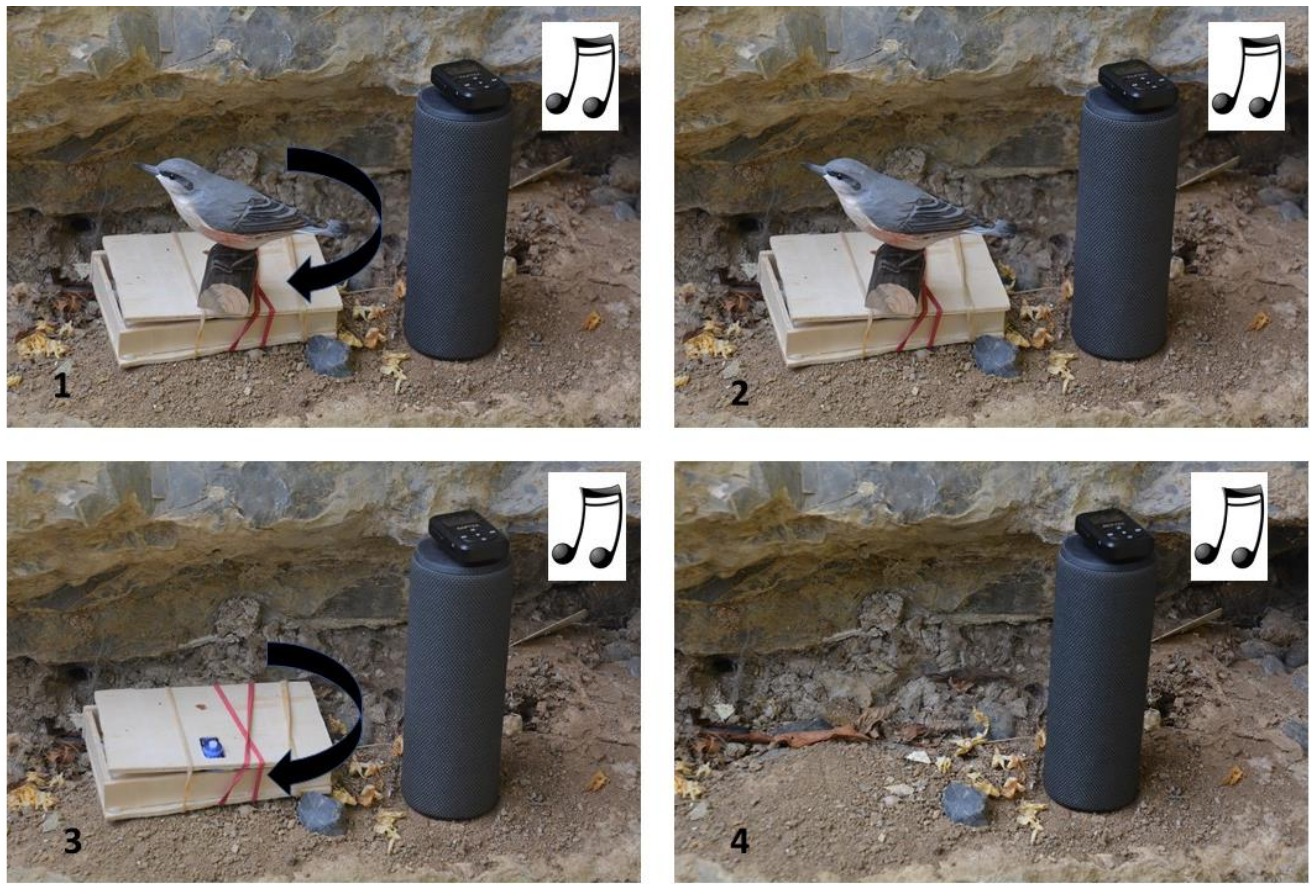

Figure 1. Schematic presentation of the robot model and playbacks. (1): Playback and animated robot model; (2): playback and motionless robot model; (3): playback and animated device without model; (4): playback only. At baseline level, setup was similar to (4), but no sounds were played.

Models were placed on the ground at the base of a tree and paired with audio playback of calls [15]. Nuthatches do not avoid the ground, they also use it for feeding [32], and similarly Templeton and Greene [40] placed their loudspeaker near the ground in experiments with the red-breasted nuthatches (Sitta canadensis). The same model was used throughout the experiment (www.wildlifegarden.de). This was obtained to provide a standardized stimulus [35]. In all cases, conspecific calls were played back for $5 \mathrm{~min}$. A total of seven call sequences were used for the playbacks (Table 1). For the standardization, we used the same call sequence/playback for every experiment on the same plot but used different call sequences for different sites, following Akçay et al. [11], who also varied only one factor (mount versus no mount), and also kept the song identical. We used calls rather than song because calls of nuthatches can be heard during the whole year (see also our baseline measurements).

Table 1. Overview of the calls (stimuli) for the construction of the playback tapes.

\begin{tabular}{ccc}
\hline Source & Location & Territories Used \\
\hline Kleiber Bergmann & DVD & 2 \\
\hline https://www.xeno-canto.org/418019 & Heidelberg/BW/Germany & 2 \\
\hline https://www.xeno-canto.org/489437 & Spreewald/BB/Germany & 1 \\
\hline https://www.xeno-canto.org/399395 & Augsburg/BY/Germany & 3 \\
\hline https://www.xeno-canto.org/118485 & Roccatederighi, Grosseto/Italy & 1 \\
\hline https://www.xeno-canto.org/127154 & Berlin/Germany & 1 \\
\hline https://www.xeno-canto.org/206405 & Stromberg/BW/Germany & 2 \\
\hline
\end{tabular}

The robot model consisted of a wooden model of a nuthatch mounted onto a computer-assisted small platform. The robot was animated with an Arduino paradisetronic.com pro micro module with ATmega32U4, Arduino Leonardo Board imitation, $5 \mathrm{~V}, 16 \mathrm{MHz}$. We controlled the rotation of the model in a randomized program to avoid stereotypic behavior by a simple computer program. 
The nuthatch was turning the whole body and axis around with different angles, and therefore creating the representation that an individual was moving in a left-right movement (for an example with great tits Parus major, see: https://www.youtube.com/watch? $\mathrm{v}=$ wMuVnky6lTk). The Arduino processor was combined with a $9 \mathrm{v}$ battery pack and connected to a AZDelivery SG90 micro servo motor $9 \mathrm{G}$ for helicopters. A mmtrade battery clip for $9 \mathrm{v}$ was connected with the $9 \mathrm{v}$ battery. To start and stop the model, a toggle switch (2 pole rocker switch) was used.

Playbacks of calls were broadcast using a portable Bluetooth loudspeaker Ultimate Ears Boom 2 (Ultimate Ears, Irvine/Newark) and an mp3 player AGPTEK A26 (AGPTEK). All stimuli were standardized to be five minutes long (playback time $=$ observation time). We set the speaker playback output to $75 \mathrm{dBSPL}$ (sound pressure level) measured in the lab at $1 \mathrm{~m}$ from the speaker using a PeakTech 8005 sound level meter (PeakTech Prüf- und Messtechnik GmbH, Gerstenstieg 4, 22,926 Ahrensburg, Germany; see [41]). This is comparable to their natural loudness. After the setup of the experiment, the observer retreated to about $\approx 20 \mathrm{~m}$ (mean $\pm \mathrm{sd}: 19.08 \pm 3.9 \mathrm{~m}$ ). The distance towards the setup was uncorrelated to the response intensity $(\mathrm{r}=0.056, p=0.707, n=48)$. To reduce possible habituation to the experimental trials, there was an interval of at least 1 day between trials on the same pair [35], although in most cases the difference was higher (e.g., 3 days in-between trials were used by Akçay et al. [11]). Differences between the playback experiments were 3.33 days between experiment 1 and 2 (SD $=1.15$, range 3-7), 12.25 days between experiment 2 and $3(\mathrm{SD}=3.62$, range 6-20) and, finally, 5.25 days between experiment 3 and $4(\mathrm{SD}=2.45$, range $1-8)$.

\subsection{Variables}

The following variables were noted during the playback trials or during the baseline: latency to approach (in s), latency to start calling (in s), time spent in the same tree (in s), number of flyovers over the model/loudspeaker, minimum distance to the model/loudspeaker (direct, in $\mathrm{m}$ ), number of individuals participating (1 or 2), number of flights into and out of the tree where the model/loudspeaker was placed, number of calls. To measure time, a stopwatch was used and to measure number of calls, a mechanical handpiece counter was used. Distances between the model/loudspeaker were measured by a ruler and by a Nikon Aculon distance meter. The Nikon Aculon measures distances from 5-1000 m. To observe the birds, a Swarovski EL $10 \times 50$ was used. If no bird appeared during the playbacks, we used $100 \mathrm{~m}$ as minimum distance, and $6 \mathrm{~min}(360 \mathrm{~s})$ as time measure for a conservative approach. The variables latency to approach and to call, as well as minimum distance and number of calls were based on [42]. Climbing down a tree is a good measure of the mobbing behavior of red-breasted nuthatches [40]. Time spent in the same tree and minimum distances and overflights were taken from Randler et al. [6].

\subsection{Ethical Note}

This study included no animal keeping; birds were observed in their natural habitat. The study was performed in accordance with relevant laws in Germany and guidelines and regulations for nature conservancy. The nuthatches were usually noisy without any experiments (see baseline) and resumed to normal foraging behavior soon after the end of the playbacks.

\subsection{Statistical Analysis}

We analyzed difference between baseline and STI treatments, and differences between different STI treatments separately. The first one included the baseline level (control) and all four experiments $(5 \times 12=\mathrm{N}=60)$, while the second linear mixed model (LMM) was based on the experimental manipulations only $(4 \times 12=\mathrm{N}=48)$. Analysis 1 was used to show differences between a baseline level and experimental manipulations, to show that the responses to STIs are stronger than a control. Analysis 2 compared the four different experiments. Therefore, the principal component analysis and the LMM were completed twice, one for the first dataset (including baseline), and one for the comparison of the STIs. The eight variables measured were subjected to principal component factor analysis. Kaiser-Meyer-Olkin (KMO) was 0.795 (0.726 for second analysis), suggesting a good value, Bartlett's 
sphericity test was approximately $\chi^{2}=150.458 \mathrm{df}=29, p<0.001,\left(\chi^{2}=90.697 \mathrm{df}=28, p<0.001\right)$, without rotation. For further calculations, we used the factor scores of factor 1 (principal component 1 (PC1); calculated as regression scores) as the dependent variable in a LMM. Higher scores on factor 1 represent stronger responses to the stimulus presentation. In model 1, only the type of stimulus presentation was analyzed to show the influence of the baseline (without any experimental manipulation). In the second model, the call playback tape (Table 1) was used as a random factor, site as random and as a repeated measure with ante-dependent covariance matrix. Order of presentation and experimental manipulation (playback, model, model and playback, playback and device without model) as fixed factor (Outcome PC1 regression | FIXED = type_code order type_code*order | RANDOM = sound site| REPEATED = type_code $\mid$ SUBJECT(Sites) COVTYPE(AD1)). In addition, we correlated the differences in days between the playback experiments with the response variable PC1 using Pearson's correlation. All statistics have been carried out with SPSS 26 (IBM, Armonk, NY, USA).

\section{Results}

The descriptive data according to the four experimental conditions are shown in Table 2. In the control baseline experiments, nuthatches did not approach, but called (Table 2).

Table 2. Nuthatch behavior (outcome variables) according to the four experimental conditions and the control baseline. The experimental conditions are numbered in the same way as in Figure 1.

\begin{tabular}{ccccccccc}
\hline Type & $\begin{array}{c}\text { Latency to } \\
\text { Approach } \\
\text { (s) }\end{array}$ & $\begin{array}{c}\text { Latency to } \\
\text { Call (s) }\end{array}$ & $\begin{array}{c}\text { Fly } \\
\text { Overs }\end{array}$ & $\begin{array}{c}\text { Time Spent } \\
\text { in Same } \\
\text { Tree (s) }\end{array}$ & $\begin{array}{c}\text { Minimum } \\
\text { Distance } \\
\text { (m) }\end{array}$ & Calls & Individ. & $\begin{array}{c}\text { In \& Out } \\
\text { Tree }\end{array}$ \\
\hline $\begin{array}{c}\text { Control/ } \\
\text { baseline } \\
\text { Call \& } \\
\text { animated } \\
\text { model (1) }\end{array}$ & 360 & 182 & 0.0 & 0.0 & 58.6 & 15.2 & 0.83 & 0.0 \\
$\begin{array}{c}\text { Call \& } \\
\text { motionless } \\
\text { model (2) }\end{array}$ & 137 & 125 & 0.92 & 67.00 & 19.6 & 90 & 1.67 & 1.25 \\
$\begin{array}{c}\text { Call \& robot } \\
\text { device in } \\
\text { motion (3) }\end{array}$ & 138 & 102 & 0.50 & 29.58 & 21.4 & 78 & 1.58 & 0.50 \\
Call only (4) & 127 & 109 & 1.92 & 32.50 & 12.2 & 137 & 1.50 & 0.83 \\
\hline
\end{tabular}

Including the baseline data, the first eigen-value (3.969) of the factor analysis explained $49.6 \%$ of the variance, the second $19.2 \%$ (eigen-value $=1.539$ ). Based on the experiments only (excluding the baseline), the first eigen-value was 3.479 ( $43.5 \%$ of variance explained). The factor loadings of both analyses are depicted in Table 3. Nuthatches are noisy birds. During the baseline level, in 10 out of 12 cases, spontaneous calling occurred (binomial test, $p=0.039$ ). Thus, calling activity of nuthatches was high, concerning the study sites and dates.

In the LMM including baseline, there was a highly significant effect of treatment $(\mathrm{F}=9.277, \mathrm{df}=4$, $p<0.001$ ). Post-hoc comparisons showed significant differences between the baseline measures and all of the four experimental manipulations ( $p$ always $<0.001)$. Thus, nuthatches responded more strongly towards any of the stimulus presentations than towards a negative control. This confirms that nuthatches show a territorial response towards STIs in the non-breeding season. 
Table 3. Results of principal component analysis of the outcome variables. Factor loadings are shown for the sample including the baseline $(\mathrm{N}=60)$, and the sample without baseline focusing on the comparison of the four simulated territorial intrusions (STIs) $(\mathrm{N}=48)$.

\begin{tabular}{ccc}
\hline & $\begin{array}{c}\text { Factor } \mathbf{1} \\
\text { Including Baseline } \\
\mathbf{( N = 6 0 )}\end{array}$ & $\begin{array}{c}\text { Factor 1 } \\
\text { STI Experiments Only } \\
\mathbf{( N = 4 8 )}\end{array}$ \\
\hline Latency to approach & -0.861 & -0.811 \\
Latency to call & -0.603 & -0.556 \\
Time spent in the same tree & 0.724 & 0.722 \\
fly-overs & 0.582 & 0.573 \\
Minimum distance (m) & -0.866 & -0.823 \\
individuals & 0.771 & 0.643 \\
flights into the tree & 0.678 & 0.659 \\
calls & 0.444 & 0.371 \\
\hline
\end{tabular}

The second LMM showed a significant influence of order, but not of stimulus presentation, nor of the interaction between both (see Table 4; Figures 2 and 3). Site as a random factor was not significant and explained about $6 \%$ of the variance.

Table 4. Results of the linear mixed model with response (principal component scores, PC1) as outcome.

\begin{tabular}{ccccc}
\hline Source & $\mathbf{d f}$ & $\mathbf{d f}$ & $\mathbf{F}$ & $\boldsymbol{p}$ \\
\hline Constant & 1 & 8.026 & 0.005 & 0.947 \\
Stimulus & 3 & 10.958 & 1.000 & 0.429 \\
Order & 3 & 18.283 & 10.219 & $<0.001$ \\
Stimulus ${ }^{*}$ order & 9 & 13.486 & 1.069 & 0.441 \\
\hline
\end{tabular}

* represents an interaction term.

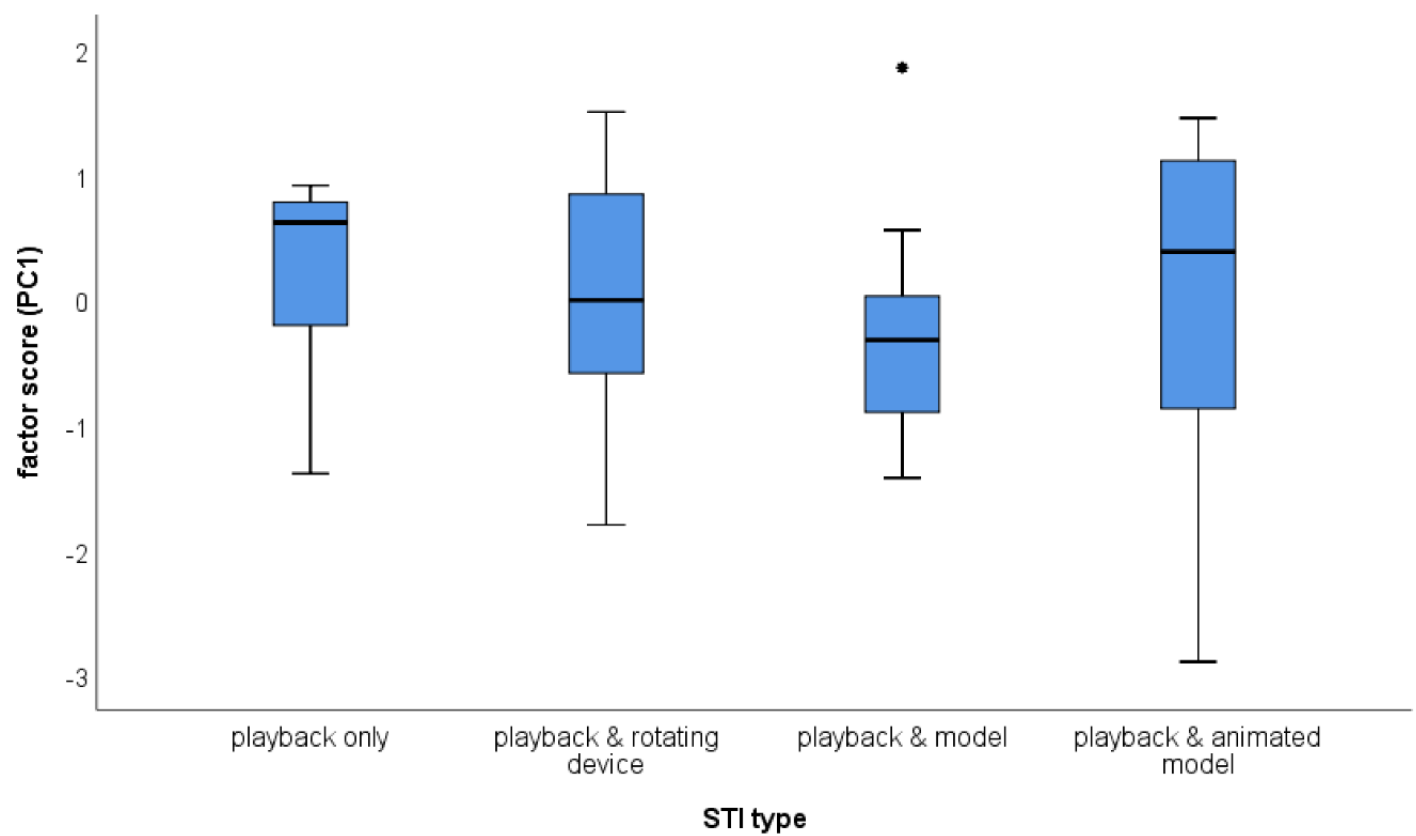

Figure 2. Responses towards the four different stimuli concerning PC1. Higher scores represent stronger response. Boxplots show the median and the interquartile range (25/75 percentile), whiskers show the range. Outliers are indicated separately as dot. 


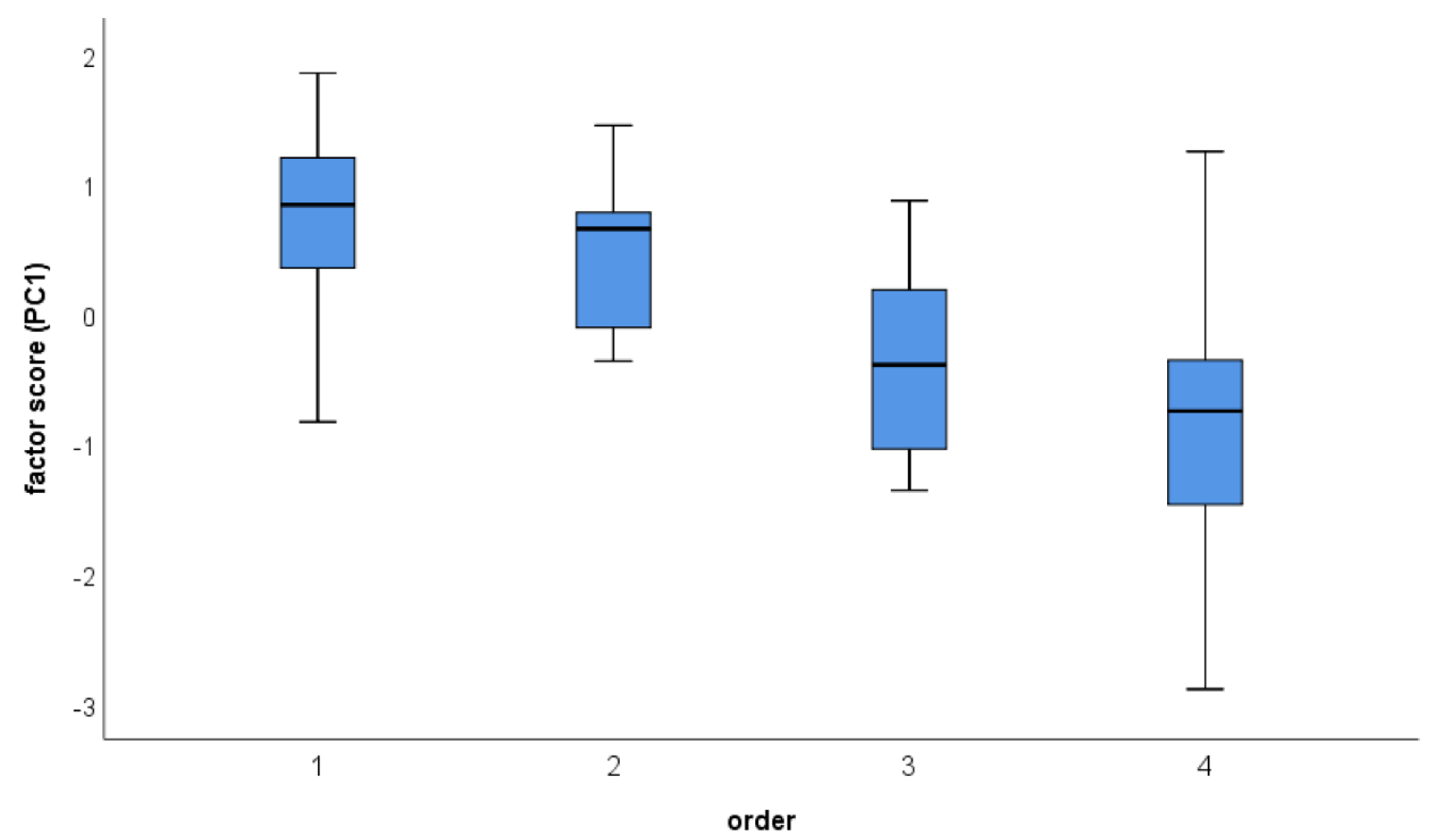

Figure 3. Responses of nuthatches according to the presentation order. Higher scores represent stronger response. Boxplots show the median and the interquartile range (25/75 percentile), whiskers show the range. Outliers are indicated separately.

However, the variation in response was highest in the animated model treatment (see Figure 2), suggesting that the animated robot model produces ambivalent responses or responses with large inter-individual differences.

Concerning order effects, a significant decrease in response was found related to order. Thus, responses towards the experiments were lowest in the last experiment.

Correlations between the strength of the response (PC1) and the difference in days between the STI experiments were all non-significant and coefficients were 0.206 (day1-day2), 0.223 (day2-day3), and -0.342 (day3-day4).

\section{Discussion}

Nuthatches responded stronger towards the experiments as compared to the baseline without any experimental manipulations. The responses towards the STI experiments were somewhat unexpected because we predicted a stronger response towards the experiments with the animated robot model compared to the unanimated decoy or towards the playback stimulus alone. However, a similar situation was found in veeries, who responded similarly to all types of stimuli presented [17]. In contrast, in song sparrows, Melospiza melodia, Akçay et al. [11] found a higher aggression in some variables when comparing playbacks with a combination of playback and mount. It probably strongly depends on species, e.g., when comparing species inhabiting open habitats, such as grassland versus species inhabiting dense forests. In addition, it may also depend on the form of courtship display and amplitude of the song. Further, it may be different during the breeding season. However, there are- to our knowledge-no studies examining territorial responses towards STIs in a species comparing breeding and non-breeding season. Additionally, the variation was highest in the animated robot experiment (Figure 2). This raises the question of whether simple playbacks or playbacks in combination with an unanimated model would elicit the same responses in other species as in our study. This would be beneficial for experimental STIs when playback experiments (without models or animation) might be sufficient.

We found a highly significant order effect. That is, the response decreased with every presentation irrespective of the experimental condition. These are interesting results because we had on average 
a couple of days between the experiments. As there was no significant interaction between order effect and experimental condition, the counterbalanced order of the presentation had no influence on the experimental conditions. The correlations between the experiments were inconclusive. Between experiment 1 and 2, as well as between experiment 2 and 3 , longer periods of time led to a stronger response (not significant), while between experiment 3 and 4 , longer duration led to a lower response. The order effect can be interpreted in different ways: First, it could be seen as evidence that even a longer delay of some days between subsequent experiments are insufficient to avoid habituation. This could be analyzed in further studies with variation in delays between experiments. Additionally, a subsequent study should compare such dependent experiments within the same territory with experiments where nuthatches were tested in their territory only once. Apart from habituation, there could have been a seasonal influence of the progressing fall season. Therefore, such STIs in nuthatches might be studied over a longer period in fall and probably throughout the winter season.

The study confirmed that nuthatches also show territorial responses towards intruders in the non-breeding season in autumn [31,32]. In some studies, nuthatches have attacked the decoys or models [32], and this was not found in our present study. However, this could be a seasonal effect because aggressiveness is weaker outside the breeding season. Aggressive responses of adult male nuthatches towards conspecific live male decoys were significantly stronger during the breeding season than during autumn [8], and males only showed elevated testosterone levels during the breeding season [8]. In contrast, resident stonechats (Saxicola torquata) did not show seasonal changes either in the latency until first attack or in the minimum distance of approach to a model [26]. Interestingly, Matthysen [9] reported that aggression in nuthatches towards a live decoy was even stronger in autumn compared to spring. Taken together, these results suggest that more detailed studies are needed to portray the aggressive response against STI in nuthatches and that the present study can only generalize for non-breeding territorial aggression.

A methodological limitation is that the calls have been counted by a handheld counter rather than by audio-recording. This would have allowed us to study the call variation of the responses towards the STIs in more detail. This makes it easier to study behavior because it is cheaper and quicker using playback only. Nevertheless, the study must be extended to other species where behavior towards different STIs may differ.

As a conclusion, the current study shows that STI in nuthatches elicited similar responses, irrespective of using playback calls, or the calls in combination with an animated or unanimated model.

Author Contributions: Conceptualization, C.R., E.R.; methodology, C.R.; software, E.R.; formal analysis, C.R.; investigation, C.R.; resources, E.R.; writing-original draft preparation, C.R. All authors have read and agreed to the published version of the manuscript.

Funding: This research received no external funding.

Acknowledgments: This study is dedicated to the memory of Hans Löhrl who has been working intensely on nuthatches, and after whom the Hans-Löhrl-prize of the German Ornithological Society (DOG) was named. CR is grateful having received the Hans-Löhrl-prize for field ornithology in 2008.

Conflicts of Interest: The authors declare no conflict of interest.

\section{References}

1. Schwabl, H. Winter and Breeding Territorial Behaviour and Levels of Reproductive Hormones of Migratory European Robins. Ornis Scand. 1992, 23, 271. [CrossRef]

2. Wingfield, J.C. Regulation of Territorial Behavior in the Sedentary Song Sparrow, Melospiza melodia morphna. Horm. Behav. 1994, 28, 1-15. [CrossRef] [PubMed]

3. Lenis, P.R.; Guillermo-Ferreira, R. Effect of noise on behavioural response to simulated territorial intrusion in the Great Kiskadee (Pitangus sulphuratus) (Aves: Tyrannidae). Urban Ecosyst. 2019, 23, 93-96. [CrossRef]

4. Ansell, D.; Magrath, R.D.; Haff, T.M. Song matching in a long-lived, sedentary bird with a low song rate: The importance of song type, song duration and intrusion. Ethology 2020, 126, 1098-1110. [CrossRef] 
5. Beecher, M.D.; Campbell, S.; Burt, J.M.; Hill, C.E.; Nordby, J. Song-type matching between neighbouring song sparrows. Anim. Behav. 2000, 59, 21-27. [CrossRef]

6. Randler, C.; Förschler, M.I.; González, J.; Aliabadian, M.; Bairlein, F.; Wink, M. Phylogeography, pre-zygotic isolation and taxonomic status in the endemic Cyprus Wheatear Oenanthe cypriaca. J. Ornithol. 2012, 153, 303-312. [CrossRef]

7. Jin, L.; Liang, J.; Fan, Q.; Yu, J.; Sun, K.; Wang, H. Male Great Tits (Parus major) adjust dear enemy effect expression in different breeding stages. J. Ornithol. 2020, 1-9. [CrossRef]

8. Landys, M.M.; Goymann, W.; Schwabl, I.; Trapschuh, M.; Slagsvold, T. Impact of season and social challenge on testosterone and corticosterone levels in a year-round territorial bird. Horm. Behav. 2010, 58, 317-325. [CrossRef]

9. Matthysen, E.R.I.K. Some observations on sex-specific territoriality in the nuthatch. Ardea 1986, 74, 177-183.

10. Tryjanowski, P.; Morelli, F.; Osiejuk, T.S.; Møller, A.P. Functional significance of cuckoo Cuculus canorus calls: Responses of conspecifics, hosts and non-hosts. PeerJ 2018, 6, e5302. [CrossRef]

11. Akçay, Ç.; Tom, M.E.; Holmes, D.; Campbell, S.E.; Beecher, M.D. Sing softly and carry a big stick: Signals of aggressive intent in the song sparrow. Anim. Behav. 2011, 82, 377-382. [CrossRef]

12. Darolová, A.; Krištofík, J.; Knauer, F.; Hoi, H. Behavioural response of Eurasian Blackcaps to acoustically simulated conspecific and heterospecific male intruders. J. Ornithol. 2020, 161, 447-458. [CrossRef]

13. Laidre, M.E.; Vehrencamp, S.L. Is bird song a reliable signal of aggressive intent? Behav. Ecol. Sociobiol. 2007, 62, 1207-1211. [CrossRef] [PubMed]

14. Tryjanowski, P.; Morelli, F.; Kwieciński, Z.; Indykiewicz, P.; Møller, A.P. Birds respond similarly to taxidermic models and live cuckoos Cuculus canorus. J. Ethol. 2018, 36, 243-249. [CrossRef]

15. Bentz, A.B.; Philippi, K.J.; Rosvall, K.A. Evaluating seasonal patterns of female aggression: Case study in a cavity-nesting bird with intense female-female competition. Ethology 2019, 125, 555-564. [CrossRef]

16. Patricelli, G. Robotics in the Study of Animal Behavior. In Encyclopedia of Animal Behavior; Elsevier BV: Amsterdam, The Netherlands, 2010; Volume 3, pp. 91-99.

17. Belinsky, K.L.; Nemes, C.E.; Schmidt, K.A. Two Novel Vocalizations Are Used by Veeries (Catharus fuscescens) during Agonistic Interactions. PLoS ONE 2015, 10, e0120933. [CrossRef]

18. Ręk, P.; Magrath, R.D. Multimodal duetting in magpie-larks: How do vocal and visual components contribute to a cooperative signal's function? Anim. Behav. 2016, 117, 35-42. [CrossRef]

19. Carlson, N.V.; Pargeter, H.M.; Templeton, C.N. Sparrowhawk movement, calling, and presence of dead conspecifics differentially impact blue tit (Cyanistes caeruleus) vocal and behavioral mobbing responses. Behav. Ecol. Sociobiol. 2017, 71, 133. [CrossRef]

20. Frohnwieser, A.; Murray, J.C.; Pike, T.W.; Wilkinson, A. Using robots to understand animal cognition. J. Exp. Anal. Behav. 2016, 105, 14-22. [CrossRef]

21. Krause, J.; Winfield, A.F.T.; Deneubourg, J.-L. Interactive robots in experimental biology. Trends Ecol. Evol. 2011, 26, 369-375. [CrossRef]

22. Barnett, C.A.; Sakaluk, S.K.; Thompson, C.F. Aggressive displays by male House Wrens are composed of multiple components that predict attack. J. Field Ornithol. 2014, 85, 56-62. [CrossRef]

23. Billerman, S.M.; Carling, M.D. Differences in aggressive responses do not contribute to shifts in a sapsucker hybrid zone. Auk Ornithol. Adv. 2017, 134, 202-214. [CrossRef]

24. Byers, B.E. Chestnut-sided warblers use rare song types in extreme aggressive contexts. Anim. Behav. 2017, 125, 33-39. [CrossRef]

25. Randler, C. Verhaltensbiologie; Haupt Verlag: Bern, Switzerland, 2018.

26. Marasco, V.; Fusani, L.; Dessì-Fulgheri, F.; Canoine, V. Non-migratory stonechats show seasonal changes in the hormonal regulation of non-seasonal territorial aggression. Horm. Behav. 2011, 60, 414-419. [CrossRef] [PubMed]

27. Enoksson, B.; Nilsson, S.G. Territory Size and Population Density in Relation to Food Supply in the Nuthatch Sitta europaea (Aves). J. Anim. Ecol. 1983, 52, 927. [CrossRef]

28. Goymann, W.; Landys, M.M. Testosterone and year-round territoriality in tropical and non-tropical songbirds. J. Avian Biol. 2011, 42, 485-489. [CrossRef]

29. Bezzel, E. Kompendium der Vögel Mitteleuropas. 2. Passeres-Singvögel; Aula-Verlag: Wiesbaden, Germany, 1993.

30. Löhrl, H. Die Kleiber Europas. Neue Brehm Bücherei, 2nd ed.; A. Ziemsen Verlag: Lutherstadt—Wittenberg, Germany, 1967; p. 120. 
31. Matthysen, E. The Nuthatches; TAD Poyser: London, UK, 1998; p. 315.

32. Löhrl, H. Das Verhalten des Kleibers (Sitta europaea caesia Wolf). Z. Tierpsychol. 2010, 15, 191-252. [CrossRef]

33. Enoksson, B. Autumn Territories and Population Regulation in the Nuthatch Sitta europaea: An Experimental Study. J. Anim. Ecol. 1990, 59, 1047. [CrossRef]

34. Matthysen, E. Behavioral and ecological correlates of territory quality in the Eurasian Nuthatch (Sitta europaea). Auk 1990, 107, 86-95.

35. Nad'o, L.; Kašová, M.; Krištín, A.; Kaňuch, P. Cooperative nest-defence behaviour and territory quality in a resident and socially monogamous passerine. Ethology 2018, 124, 514-526. [CrossRef]

36. Randler, C. Ein Beitrag zum Invasionsvogel Kleiber Sitta europaea caesia. Ornithol. Jahresh. Bad. Württ. 1997, 13, 145-160.

37. Kalb, N.; Anger, F.; Randler, C. Subtle variations in mobbing calls are predator-specific in great tits (Parus major). Sci. Rep. 2019, 9, 6572. [CrossRef] [PubMed]

38. Kalb, N.; Anger, F.; Randler, C. Great tits encode contextual information in their food and mobbing calls. R. Soc. Open Sci. 2019, 6, 191210. [CrossRef]

39. Altmann, J. Observational Study of Behavior: Sampling Methods. Behaviour 1974, 49, 227-266. [CrossRef] [PubMed]

40. Templeton, C.N.; Greene, E. Nuthatches eavesdrop on variations in heterospecific chickadee mobbing alarm calls. Proc. Natl. Acad. Sci. USA 2007, 104, 5479-5482. [CrossRef] [PubMed]

41. Kalb, N.; Randler, C. Behavioral responses to conspecific mobbing calls are predator-specific in great tits (Parus major). Ecol. Evol. 2019, 9, 9207-9213. [CrossRef]

42. White, P.J.C. Song characteristics vary clinally across an active colonization zone in Eurasian Nuthatches Sitta europaea. Bird Study 2012, 59, 296-302. [CrossRef]

Publisher's Note: MDPI stays neutral with regard to jurisdictional claims in published maps and institutional affiliations. 